\title{
Billionfold Data Increase from Mass Spectrometry Instrumentation*
}

\author{
Fred W. McLafferty \\ Baker Chemistry Laboratory, Cornell University, Ithaca, New York, USA
}

\begin{abstract}
The mass spectrometers of 1910-1950 gave 10-100 separately measurable mass values (resolution increments) in a single spectrum; the few other analytical methods then with this capability, such as emission spectroscopy, were not suitable for molecular characterization. The introduction of high-resolution mass spectra 40 years ago gave a $10^{2}$ increase in resolution increments, while tandem mass spectrometry $\left(\mathrm{MS}^{2}\right) 30$ years ago promised a similar exponential gain. A key to the present realization of this was the discovery of Fourier-transform mass spectrometry 20 years ago, while electrospray ionization of large molecules 10 years ago greatly extended the upper mass limit of spectra. These improvements can now give $10^{5}-10^{6}$ resolution increments in the mass spectrum of a large molecule. Extending this with $\mathrm{MS}^{2}$ ions in any of $>10^{4}$ mass regions can be dissociated to produce a mass spectrum with these $>10^{5}$ resolution increments. With the several steps of MS $^{n}$ now achievable, this represents a $>10^{9}$ data gain since 1950 . However, utilization of this amazing capability is in its infancy, presenting a tremendous challenge for our field. (c) 1997 American Society for Mass Spectrometry (J Am Soc Mass Spectrom 1997, 8, 1-7)
\end{abstract}

$\mathrm{G}$ ravimetric and volumetric analyses, the standard chemical measurement methods for over a century, provided only a single value per analysis. These yielded quantitative measurement of a preselected ("targeted") elemental species, in contrast to spectroscopy in which emission lines could be measured at many different wavelengths (many "resolution increments") to provide identifications of a variety of elements. A similar advantage of mass spectrometry (MS) as an analytical tool, especially applicable to the identification of unknown molecules, has always been its multiplicity of data in a single spectrum. The famous 1912 mass spectrum from J. J. Thomson's "parabola" instrument showed peaks at $\mathrm{m} / \mathrm{z} 20$ and 22 that we now know are due the neon isotopes; Aston's [1a] spectrum records peaks from $m / z 1$ to 200 (Figure 1). Ten different ionic components are identified in this spectrum; for the mass spectrum of an unknown, ions should have been identifiable at an even larger number of different mass values (resolution increments). Gentler ionization methods for volatile molecules and MS instruments with unit resolution increased this to at least 100 resolution increments in a single spectrum, and in the 1950s this was raised dramatically by a $10^{2}$ increase in resolving power. By measuring another mass spectrum from each peak in a mass spectrum, tandem mass spectrometry $\left(\mathrm{MS}^{n}\right)$ made possible a further exponential in-

Address correspondence to Dr. Fred W. McLafferty, Baker Chemistry Laboratory, Cornell University, Ithaca, NY 14853-1301.

* Presented in the symposium on History of Mass Separation Techniques, ASMS Meeting, Portland, OR, May 1996. crease in resolution increments. Recent capabilities to ionize and dissociate molecules that are orders of magnitude larger to measure their $\mathrm{MS}^{n}$ spectra with even higher resolving power provides $>10^{9}$ increase in resolution increments in comparison to the MS capabilities of 1950 [2].

\section{Unit Resolving Power}

The first commercial analytical MS instrument, introduced in 1940, gave quantitative $( \pm 1 \%)$ abundance values for up to 20 components in mixtures of light hydrocarbon gases [2]; a 20 component analysis requires the accurate measurement of at least 20 peaks. These occurred essentially at integral mass values, so that unit resolution was an instrument necessity.

There were early indications that MS could also be used for the identification and structural characterization of unknown molecules; $\mathrm{CO}_{2}$ ions have been assigned in Figure 1. Aston's [1b] 1922 book shows photographic plate spectra (Figure 2) of $\mathrm{BF}_{3}, \mathrm{AsH}_{3}$, and $\mathrm{CS}_{2}$ (VIII, labeled $\mathrm{SO}_{2}$ ), with peaks corresponding to $\mathrm{CS}_{2}^{+}, \mathrm{CS}^{+}$(also $\mathrm{CO}_{2}^{+}$?), and $\mathrm{CSO}^{+}$(impurity). The spectra of $\mathrm{SiF}_{4}, \mathrm{CH}_{3} \mathrm{Br}$, and $\mathrm{SO}_{2}$ indicate extensive pyrolysis (the ions were generated in a $20-50-\mathrm{kV}$ discharge). Electron ionization (EI) of gases gave far less decomposition [3]: in 1932, Lander of Cornell University (not my student!) reported the EI mass spectrum of benzene (Figure 3) [3c]. Reflecting our experimental challenges since then, he stated "Large molecules introduce additional difficulties to the mass-spectrograph technique. High resolving power at large molec- 


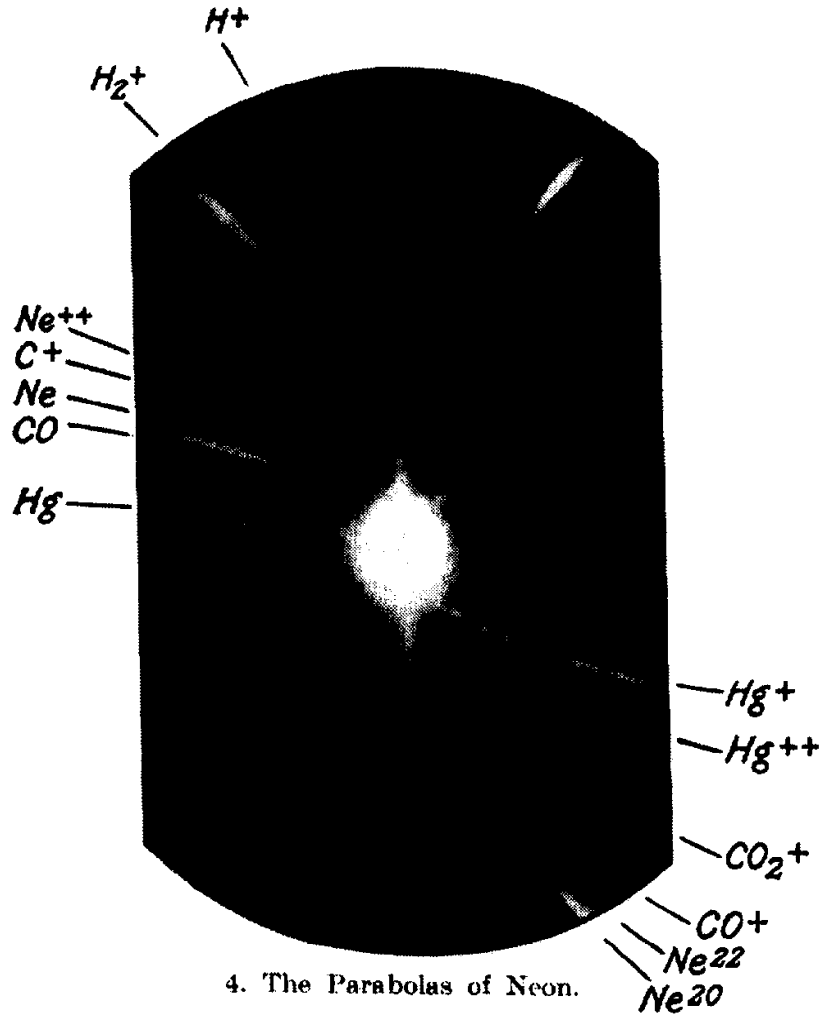

Figure 1. The parabolas of neon isotopes 20 and 22 (lower right) from J. J. Thomson's "parabola" instrument [1a].

ular weights is necessary, which requires the use of strong electric and magnetic fields, and slits as narrow as possible. The intensity is usually low because of the narrowness of the slits, and also because the ions are

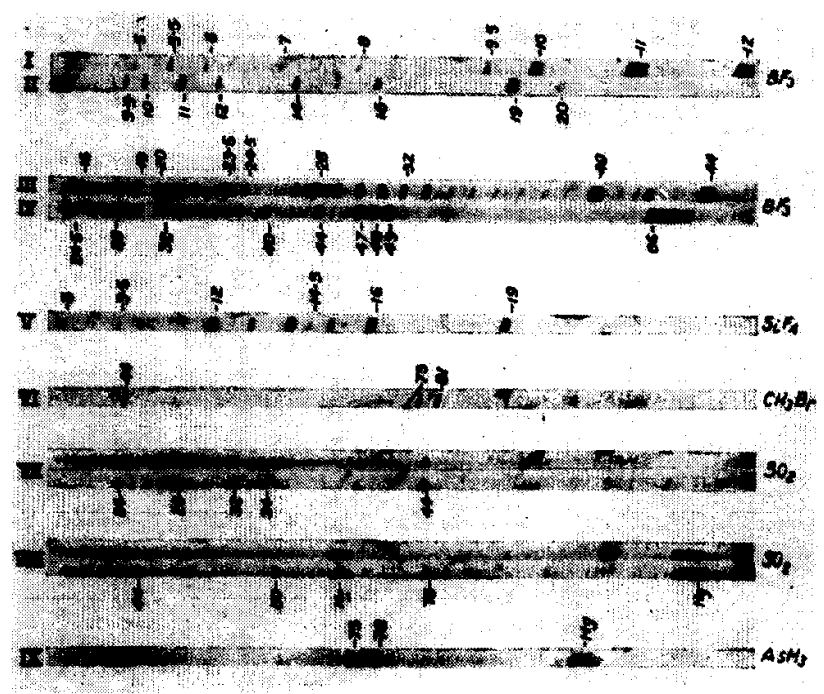

Figure 2. Photoplate mass spectra of molecules measured with Aston's mass spectrogragh [1b].

spread out over a large number of peaks. Furthermore, thermal dissociation at the filament must be eliminated, this problem being more acute with large molecules since they are in general more readily decomposed by heat."

\section{Mass Spectrometry Instruments for Molecular Identification}

Although the use of MS for gas mixture analysis grew explosively during WW II and the decade thereafter, more reports began to appear on MS attributes for

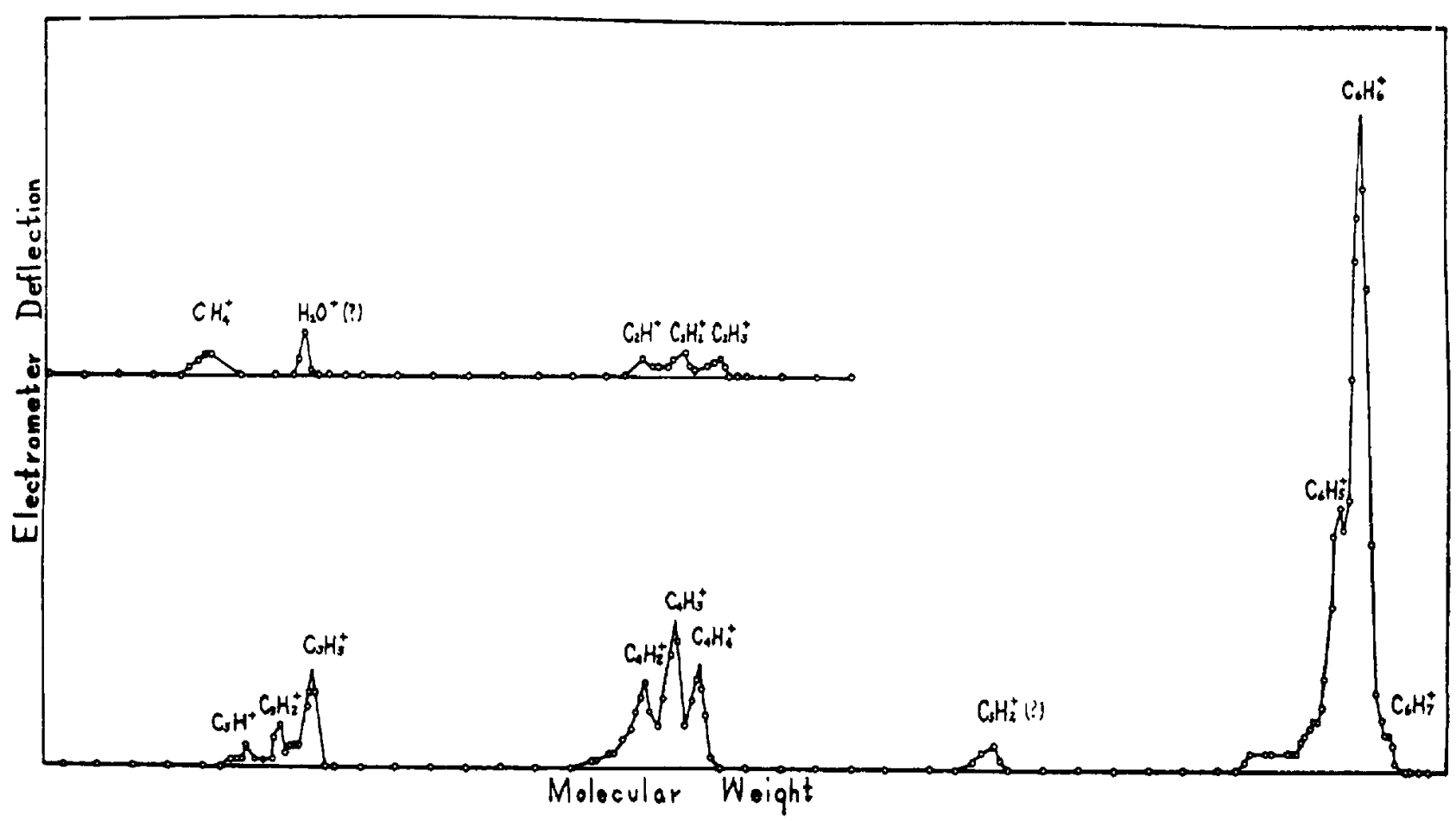

Figure 3. The 1932 electron ionization (120-V) mass spectrum of benzene [3c]. 
unknown molecule identifications [4] that led to a rapid development of this field in the following decade [5]. Improvements in research and commercial instruments were critical in this progress. Visible chart records replaced photographic methods so that the operator could monitor the spectrum during the long 30-min scan time (although the point-by-point recording of Figure 3 required a far longer time), and systems such as the "teflon slug" method were developed to measure and introduce a few milligrams of liquid and solid samples [6]. Unit resolution spectra were recorded over a 150-200-mass unit range, providing $>10^{2}$ resolution increments of data in a spectrum. With special sample introduction techniques, mass spectra could be obtained from $10^{-6} \mathrm{~mol}$ of an unknown, an unusually low amount then even for analytical techniques providing singular measurement values. Unknown identification was aided by spectral correlations [5] and reference collections [7].

\section{Gas Chromatography / Mass Spectrometry}

The rate of MS data production was increased dramatically by the 1955 invention of the Wiley-McLaren time-of-flight (TOF) instrument, whose $10^{-4}-10^{-5}$ per spectrum time requirement is still the fastest today for a commercial instrument [8]. This made possible [9] the on-line oscilloscope display of mass spectra of components as they were eluted from the gas chromatograph (Figure 4). Few laboratories used these gas chromatography/mass spectrometry (GC/MS) spectra routinely because of their poor dynamic range and the difficulty of obtaining digital mass and abundance information; this can be illustrated by attempting to identify the compound yielding Figure 4 (although Gohlke could actually do this during the GC/MS display).

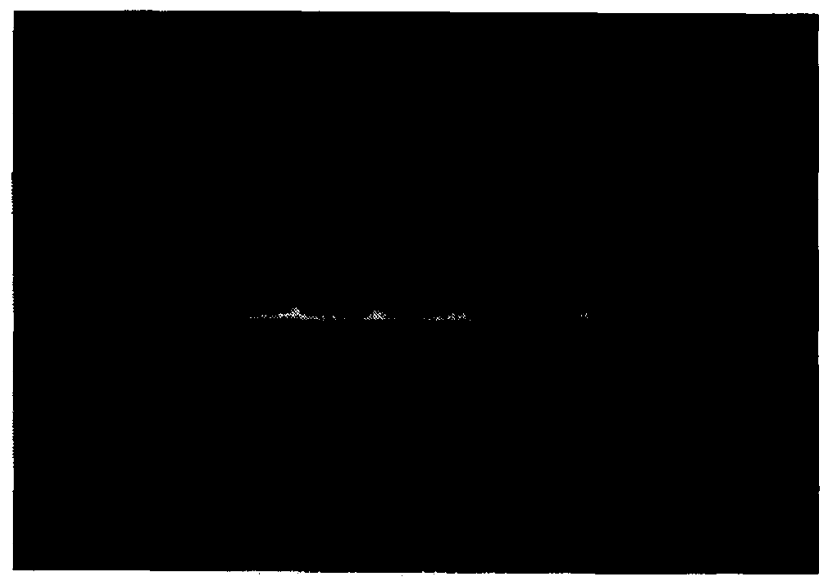

Figure 4. TOF mass spectrum (Polaroid photo of oscilloscope display) of toluene from direct GC introduction [9]. Major peaks (left to right): $m / z 39,51,65,77,91$, and 92 .

\section{Computer Data Acquisition, Reduction, and Interpretation}

Solutions to the carrier gas pumping problem, especially the jet separator [10], made GC/MS practical for most types of mass spectrometers. However, extensive analytical utilization of this great increase in "resolution increments per second" (i.e, data rate) was critically dependent on concurrent improvements in computational methodologies, whose applicability to the quadrupole gave it unusual advantages for GC/MS instrumentation [11]. Computer control gave full spectrum scans during elution of a single GC peak, with utilization of these data greatly increased by computer reduction and display of the MS data [12].

Of the several algorithms proposed for assigning structure to electron ionization [EI] spectra [7c, 13], the probability based matching (PBM) system [14] has the special features of "data weighting," shown to be critical for document retrieval from libraries [15], and "reverse searching" [14, 16]. Demanding that all the mass values of the unknown spectrum be in the reference makes difficult the matching of mixture spectra; "reverse searching" instead only demands that the reference masses be in the unknown. In contrast to an earlier comparison with the most used "forward search" system [17], PBM not only performs similarly for unknown spectra of pure compounds, but gives dramatic improvements for those of mixtures [18]. For example, with sample purity only reduced to $85 \%$ and matching criteria that retrieve $50 \%$ of possible answers, PBM gave $48 \%$ correct answers versus $17 \%$ for the forward search algorithm $(80 \%$ and $27 \%$ correct by Class IV criteria, counting structures whose mass spectra are expected to be very similar such as $m$ - versus p-xylene) [18]. The reference file of 229,000 different EI mass spectra of 198,000 compounds [19] can be searched by PBM on-line in <0.5 s [20]. Mass spectrometry is widely accepted as the primary method for identifying "global unknowns," even in mixtures, reflecting its great advantage in resolution increments, as well as speed and sensitivity, versus common methods such as NMR and IR.

\section{High Resolution}

Restricting the structural possibilities further for even more complex molecules requires more resolution increments. A pioneering advance for this was the recognition in 1954 [21] that the $10,000-20,000$ resolving power achievable with the new Nier-Johnson doublefocusing mass spectrometer made possible the identification of isobaric mass multiplets, such as a mixture of $\mathrm{O}, 15.9949$, and $\mathrm{CH}_{4}, 16.0313$. This increased the possible resolution increments by $10^{2}$, although the number of common isobaric compositions per mass unit at lower masses is $\sim 1 / 10$ of this value [22]. However, the extensive time required for exact mass measurement of a single peak seriously compounded 


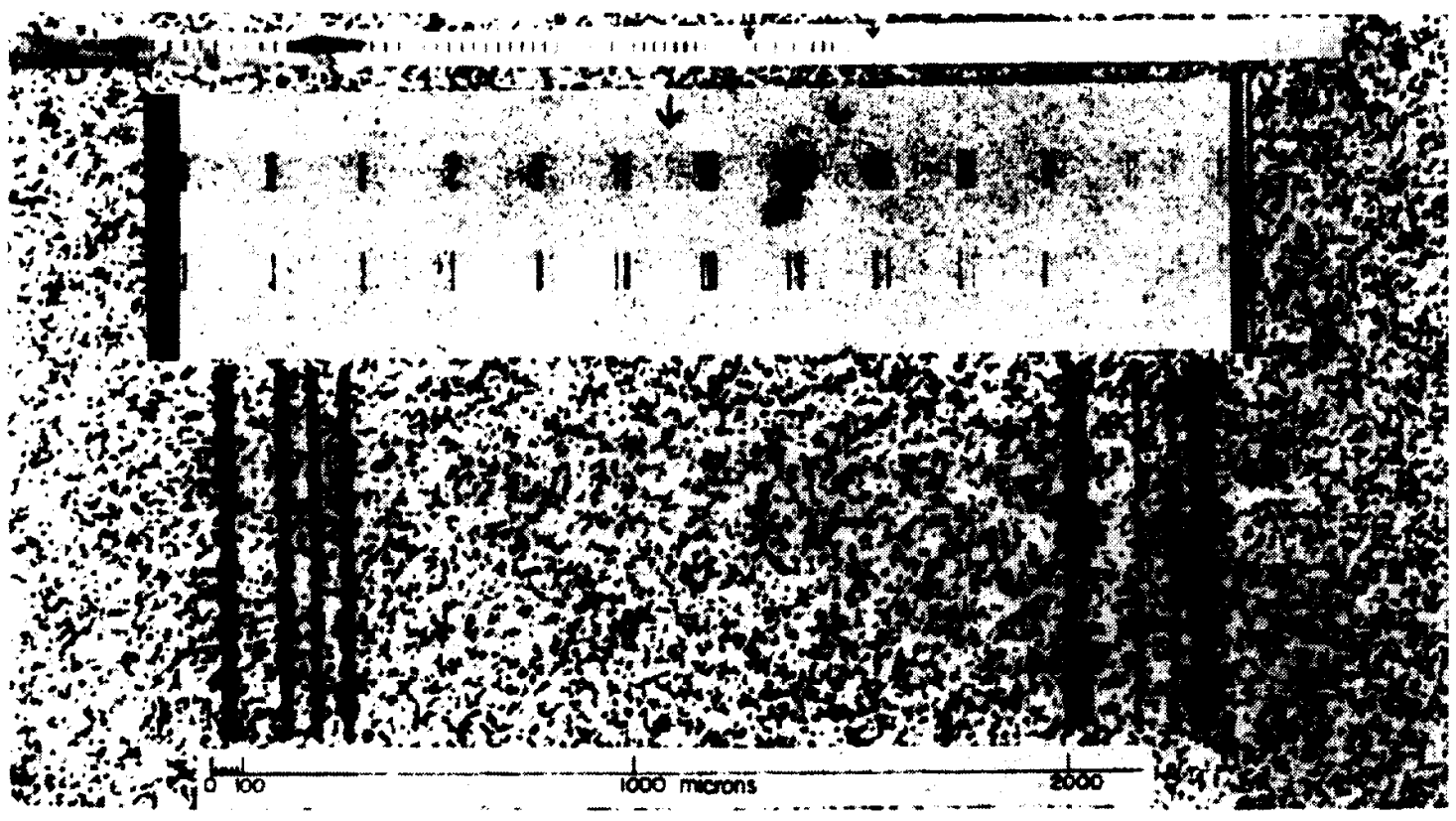

Figure 5. Photoplate mass spectrum of tetramethylcyclobutan-1,3-dione with $\mathrm{CHCl}_{3}$ internal standard. Top: $\mathrm{m} / z$ 24-141. Middle: magnification of $\mathrm{m} / z$ 77-89. Bottom: further magnification of $m / z$ 83-84; for 84, the lines represent ${ }^{92} \mathrm{C}^{35} \mathrm{Cl}^{37} \mathrm{Cl}_{r}{ }^{13} \mathrm{CHCl}_{2},{ }^{12} \mathrm{C}_{3}{ }^{13} \mathrm{CH}_{3} \mathrm{O}_{2},{ }^{12} \mathrm{C}_{4}^{13} \mathrm{CH}_{7} \mathrm{O},{ }^{12} \mathrm{C}_{5}{ }^{13} \mathrm{C}$ (hardly distinguishable), and $\mathrm{C}_{6} \mathrm{H}_{12}$ (most intense) [24].

the data problem described in the foregoing text. As an aid to this, photoplate recording with the Mattauch-Herzog system could collect all data from $\mathrm{m} / \mathrm{z}$ 20-600 simultaneously [23], but efficient reduction of such data (Figure 5) required a sophisticated photoplate reader $[23,24]$. Computer systems were also developed for Nier-Johnson scanning instruments [12], with array detectors increasing further the efficiency of these [25] and photoplate instruments.

\section{Tandem Mass Spectrometry}

A further exponential increase in MS resolution increments can be achieved by the measurement of a separate mass spectrum from the dissociation of the ions representing a single peak in a mass spectrum $\left(\mathrm{MS}^{2}\right)$; such dissociations gave "Aston bands" in early mass spectra [26]. In theory, each peak of a unit resolution MS-I spectrum that contains several hundred resolution increments could produce a MS-II spectrum with peaks that can occur in several hundred resolution increments. This MS-II spectrum can be used for further structural characterization of the peak's ions [27-29], with collisionally activated dissociation (CAD) $[28,29]$ providing far more characteristic fragments than metastable ion dissociation [27]. For unknown mixtures, a "soft ionization" MS-I spectrum can give separate molecular ion mass values for each mixture component, making chromatographic separation unnecessary, while a MS-II spectrum for dissociation of the MS-I separated molecular ion can provide structural characterization of that mixture component. Further, even a MS-II fragment ion can be characterized by an MS-III spectrum to provide more structural detail for an unknown molecule. A CAD spectrum of kilovolt energy ions is a quantitative characteristic of the fragment ion structure $[29,30]$.

\section{Tandem Mass Spectrometry Instrumentation}

The actual MS/MS data gain was small for early mass spectrometers because of serious resolution problems. Ion dissociation in a field-free region of a magnetic sector instrument gives diffuse peaks whose mass-tocharge ratio values depend on the masses of both the precursor and the product ions. These masses could be distinguished by linked scan of the sectors in a Nier-Johnson double-focusing mass spectrometer [28], by energy retardation in a time-of-flight instrument (Figure 6) [29], and by reversing the usual doublefocusing geometry so that the magnetic sector first separates the precursor ions with unit resolving power [31]. However, in all these configurations the energy released in ion dissociation gives peak spreading and

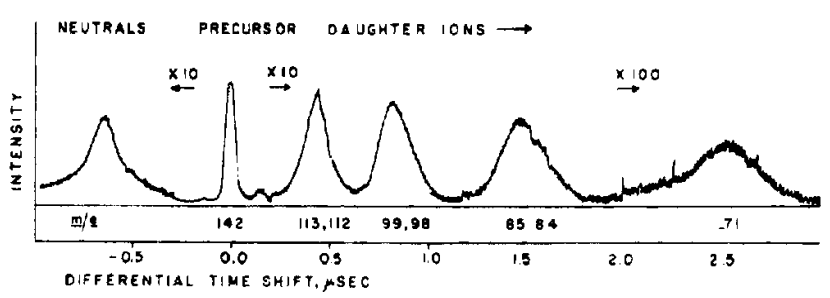

Figure 6. Time-of-flight instrument spectrum of products of metastable ion dissociation of $n$-decane that were separated by an electrostatic retarding region (neutral products not retarded) [29]. 
thus far less than unit resolving power for the MS-II spectra $(<10$ resolution increments in Figure 6). The triple quadrupole [32] and later the ion trap [33] became routine MS/MS instruments because their insensitivity to ion kinetic energy gave unit resolution in both MS-I and MS-II, with both under flexible computer control.

Obviously, adding high resolving power to $\mathrm{MS}^{n}$ would provide a far greater increase in the amount of MS data. Although this was achieved for MS-I by combining a double-focusing mass spectrometer with another mass analyzer [34], repeating this for MS-II with a tandem double-focusing mass spectrometer [34b] was far less successful. The energy released on fragmentation still seriously spread the MS-II ion image, so that even a resolving power of $10^{3}$ could only be obtained with a high sacrifice in sensitivity.

\section{Large Molecule Mass Spectra}

The number of possible mass values at which ions can be measured in a mass spectrum also depends on the mass range over which ions can be formed. Further, larger masses have a far larger number of possible ion elemental compositions. A resolving power of $10^{5}$ would provide $\sim 10^{3}$ measurable masses $(\sim 0.001-\mathrm{Da}$ wide resolution increments) in a 1-Da range at mass 84. However, for mass 84 ions (Figure 5), only $\sim 10$ monoisotopic elemental compositions represent $>90 \%$ of those found in mass spectra [19, 22]; no compositions are possible between 84.1 and 84.9. For masses 309.9-310.2, this number of possible compositions has increased to $\sim 100$, requiring a mass measuring accuracy of $2 \mathrm{ppm}$ [24]; however, there are few possible compositions for masses 310.2-310.9. These "blank regions" disappear at higher masses, so that even far higher resolving power could be useful for the mass spectra of large molecules. Their ionization has been made possible in the last decade by the development of matrix-assisted laser desorption (MALDI) [35] and electrospray ionization (ESI) [36]. The solid sample introduction of MALDI is convenient for fast routine measurement and requires only attomole samples, although its time-of-flight instrument has been handicapped by low resolving power (often $\sim 10^{2}$ at $>10 \mathrm{kDa}$ ) and poor MS/MS capabilities (Figure 6). Electrospray ionization yields multiply charged ions, advantageous for instruments whose resolving power decreases with increasing mass-to-charge-ratio, and ESI is particularly suitable for the direct introduction of liquid samples, such as for interfacing to liquid chromatography or capillary electrophoresis. Both MALDI and ESI make possible the ionization of $10^{5}-\mathrm{Da}$ or larger molecules, for whose characterization far more data would obviously be useful.

For tandem mass spectrometry of large molecules with a high number of resolution increments in each stage of MS [37], ESI has proved to be an ideal ionization method in combination with the Fourier- transform (FT) ion cyclotron resonance mass spectrometer [38]. A first fundamental advantage of FTMS is that resolving power is not affected by a variation in kinetic energy, as FTMS measures the frequency of the ion orbit in a high magnetic field; a higher kinetic energy only increases the radius of the orbit without affecting its frequency. The multiple charging of ESI produces all ions with mass-to-charge ratio values easily within the range of FTMS; Smith and co-workers [39] have even recorded molecular ions from $10^{8}-\mathrm{Da}$ DNA molecules. Resolving powers of $10^{5}-10^{6}$ are attainable even for measuring MS-II mass spectra, and the isolation [40] of precursor ions for dissociation to produce MS/MS spectra can be achieved with $>10^{4}$ resolving power [41]. With FTMS, all frequencies are measured simultaneously in approximately $1 \mathrm{~s}$, so that the Fourier transform of this time-domain data produces a spectrum recording all ions over a mass range of 500 to $>10^{5} \mathrm{Da}$. For example, purification of creative kinase (Figure 7a) has been a serious limitation in its characterization, with isoelectric focusing indicating at least three components; its ESI/FTMS spectrum is only consistent with a $\pm 2-\mathrm{Da}$ difference in the molecular masses of these components (e.g., deamidation), eliminating the possibility of methylation, phosphorylation, and other impurities (Figure 7c). Further MS/MSprovides extensive sequence confirmation and restricts the active site location [42]. Single cell and subcellular sensitivities have recently been obtained with this FTMS instrumentation utilizing nanoliterflow ESI to produce high resolution mass spectra from $<10^{-18} \mathrm{~mol}$ of biomolecules [43]. The MS/MS spectrum of $10^{-17} \mathrm{~mol}$ of carbonic anhydrase $(29 \mathrm{kDa})$ shows 10 mass values $>2.9 \mathrm{kDa}$; seven are in error by $\leq 0.1 \mathrm{Da}$, more than enough information to retrieve the correct structure from the protein data base [44].

\section{Conclusions}

The $\sim 50$ resolution increments of the 1932 mass spectrum of benzene (Figure 3) [3] were not only unusual for the time but actually would still rank high versus those of other available techniques for qualitative molecular analysis. However, for molecules as large as $10^{5} \mathrm{Da}$, an FTMS spectrum of $10^{5}$ resolving power can provide $10^{6}$ resolution increments (e.g., $10^{2}$ between masses 1000 and 1001). For $\mathrm{MS}^{n}$, a precursor ion can be isolated with a resolving power [41] of $>10^{4}$, so that ions of $10^{5}$ possible mass values (e.g., 10 between 1000 and $1001 \mathrm{Da}$ ) can be dissociated to yield an $\mathrm{MS}^{2}$ spectrum; an abundant precursor again should yield $10^{5}$ resolution increments, or a total of $10^{10}$ possible in theory for $\mathrm{MS}^{2}$. Extending this to $\mathrm{MS}^{3}$ and $\mathrm{MS}^{n}$ easily yields a $>10^{9}$ gain since 1950 . This was not only unthinkable to this mass spectrometrist then, but still beyond my wildest dreams a decade ago.

Of course a promising example such as Figure 7 only utilizes a tiny fraction of this enormous measur- 


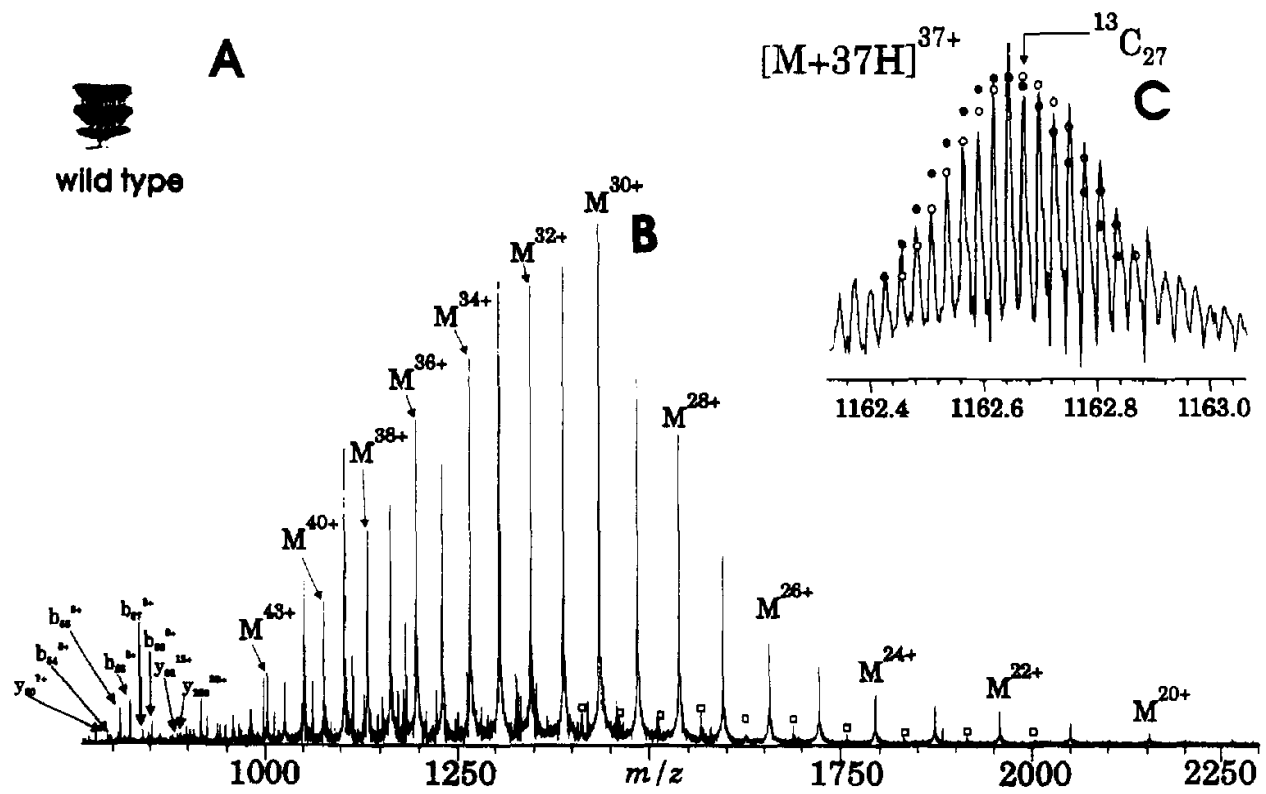

Figure 7. Rabbit muscle creatine kinase, $43 \mathrm{kDa}$. (A) Heterogeneity shown by separation on a $5 \%$ isoelectric focusing gel. (B) ESI /FTMS mass spectrum, sum of 20 scans. (C) expanded mass-to-charge ratio scale $[\mathrm{M}+37 \mathrm{H}]^{37+}$ (resolving power $\sim 10^{5}$ ) showing individual isotopic peaks; solid dots denote theoretical peak heights for molecular weight 42,981 expected from the DNA sequence, and open dots denote those expected for an equimolar mixture of unmodified, once-, and twice-deamidated enzymes (average 42,982). Lower left, fragment ions from nozzle-skimmer dissociation.

ing capability. The potential power of these multiple dimensions of unique data content for critical macromolecular applications presents professional mass spectrometrists with an unusual challenge. Quoting the philosopher DeBono, "data is not information until it has been processed into an idea."

\section{Acknowledgments}

I am convinced that this tremendous progress was made possible only by the unusual cooperation and unselfishness of the fraternity of molecular mass spectrometrists. The references herein are a very inadequate listing of all of those that have generously made possible the present capabilities that are bringing our field of mass spectrometry to an unusually high level of recognition. $\mathrm{My}$ former students and research associated deserve great credit also, as does the support of the Dow Chemical Company from 1950-1964, and since then of the National Institutes of Health, the National Science Foundation, and other generous federal funding. Finally, I am especially indebted to Mike Grayson for organizing this symposium and inviting me to contribute to it.

\section{References}

1. (a) Aston, F. W. Isotopes; Amold: London, 1922; p. 29; (b) Aston, F, W. Isotopes; Arnold: London, 1922; p. 73; (c) Phil. Mag. 1920, 39, 611-625.

2. Washburn, H. W.; Wiley, H. F.; Rock, S. M. Ind. Eng. Chem. Anal. Ed. 1943, 15, 541 .

3. (a) Dempster, A. J. Phys. Rev. 1918, 11, 316; (b) Stewart, H. R.; Olson A. R. J. Am. Chem. Soc, 1931, 53, 1246; (c) Linder, E. G. Phys. Rev. 1932, 41, 149-153; (d) Taylor, D. D. Phys. Rev. $1935,47,666$.
4. Cummings, C. S.; Bleakney, W. Phys. Rev. 1940, 58, 787; Stevenson, D. P. Disc. Faraday Soc, 1951, 10, 35; Happ, G. P.; Stewart, D. W. J. Am. Chem. Soc. 1952, 74, 4404-4408; Rosenstock, H. M.; Wallenstein, M. B.; Wahrhaftig, A. L.; Eyring, H. Proc. Nat. Acad. Science U.S.A. 1952, 38, 667; Momigny, J, Bull. Soc. Roy. Sci. Liege 1953, 22, 541; Ingold, K. U.; Lossing F. P. J. Chem. Phys. 1953, 21, 1135; Nicholson, A. J. C. Trans. Faraday Soc. 1954, 50, 1067; Ryhage, R.; Stenhagen, E.; von Sydow, Acta Chem. Scand. 1956, 10, 158; McLafferty, F. W. Anal. Chem. 1956, 28, 306; Sharkey, A. G., Jr.; Schultz, J. L.; Friedel, R. A. Anal. Chem. 1956, 28, 934-944; DeMayo, P.; Reed, R. I. Chem. Ind. (London) 1956, 1481; Rylander, P. N.; Myerson, S. J. Am. Chem. Soc. 1956, 78, 5799.

5. Beynon, J. H. Mass Spectrometry and Its Applications to Organic Chemistry; Van Nostrand: Princeton, 1960; Biemann, K. Mass Spectrometry. Organic Chemical Applications; McGraw-Hill: New York, 1962; McLafferty, F. W., Ed. Mass Spectrometry of Organic lons; Academic: New York, 1963; Budzikiewicz, H.; Djerassi, C.; Williams, D. H. Interpretation of Mass Spectra of Organic Compounds; Holden-Day: San Francisco, 1964.

6. Caldecourt, V. J. Anal. Chem. 1955, 27, 1670.

7. (a) Rock, S. M., Anal. Chem. 1951, 23, 261-268; (b) Catalog of Mass Spectral Data; Americal Petroleum Institute Project 44, Carnegie Institute of Technology: Pittsburgh; (c) McLafferty, F. W.; Gohlke, R. S. Anal, Chem. 1959, 31, 1160-1163.

8. Wiley, W. C.; McLaren, I. H. Rev. Sci. Instrum. 1955, 26, 1150-1157.

9. Gohlke, R. S.; McLafferty, F. W. J. Am. Soc. Mass Spectrom. 1993, 4, 367-371.

10. Ryhage, R. Anal. Chem. 1964, 36, 759 .

11. McFadden, W. Techniques of Combined Gas Chromatography/Mass Spectrometry; New York: Wiley, 1973.

12. Habfast, K. Adv. Mass Spectrom. 1968, 4, 3-14; Burlingame, A. L. Adv. Mass Spectrum. 1968, 4, Venkataraghavan, R.; Board, R. D.; Klimowski, R. J.; Amy, J. W.; McLafferty, F. W. Adv. Mass Spectrom. 1968, 4, 65-76; McMurry, W. J.; Lipsky, 
S. R.; Green, B. N. Adv. Mass Spectrom. 1968, 4, Halliday, J. S. Adv. Mass Spectrom. 1968, 4, 239-254.

13. McLafferty, F. W.; Loh, S. Y.; Stauffer, D. B. In Computer Enhanced Analytical Spectroscopy, Vol. II; Meuzelaar, H. C. L. Ed.; Plenum: New York, 1990; p. 163-181.

14. Pesyna, G. M.; Venkataraghavan, R.; Dayringer, H. G.; McLafferty, F. W. Anal. Chem. 1976, 48, 1362-1368.

15. Salton, G. Science 1991, 253, 974-980.

16. Abramson, F. P. Anal. Chem. 1975, 47, 45.

17. Stein, S. E.; Scott, D. R. J. Am. Soc. Mass Spectrom. 1994, 5 , 859-866.

18. McLafferty, F. W.; Zhang, M.-Y. Stauffer, D. B.; Loh, S. Y. Unpublished.

19. McLafferty, F. W.; Stauffer, D. B. Registry of Mass Spectral Data, 6th electronic ed.; Wiley: New York, 1994.

20. Bench Top PBM; Palisade Corporation, 31 Decker Road, Newfield, NY 14867.

21. Beynon, J. H. Nature 1954, 174, 735-737.

22. McLafferty, F. W.; Venkataraghavan, R. Mass Spectral Correlations, 2nd ed.; American Chemical Society: Washington, DC, 1982.

23. Biemann, K.; Bommer, P.; Desiderio, D. M. Tetrahedron Lett. $1964,1725$.

24. McLafferty, F. W. Science 1966, 151, 641-649; Venkataraghavan, R.; McLafferty, F. W.; Amy, J. W. Anal. Chem. 1967, 39, 178-185.

25. Burlingame, A. L. In Biological Mass Spectrometry: Present and Future; Matsuo, T.; Caprioli, R. M.; Gross, M. L.; Seyama, Y., Eds.; J. Wiley: New York, 1994; pp. 147-164.

26. Aston, F. W. Proc. Chem. Phil. Soc. 1919, 19, 317.

27. Shannon, T. W.; McLafferty, F. W. J. Am. Chem. Soc. 1966, 88, 5021 .

28. Jennings, K. R. Int. I. Mass Spectrom. Ion Phys. 1968, 1, 227.

29. Haddon, W. F.; McLafferty, F. W. J. Am. Chem. Soc. 1968, 90, 4745; Anal. Chem. 1969, 41, 31-36.
30. McLafferty, F. W.; Bente, P. F., III; Kornfield, R.; Tsai, S.-C.; Howe, I. J. Am. Chem. Soc. 1973, 95, 2120.

31. Lohle, V; Ottinger, C. Proceedings of the 17th Annual Conference on Mass Spectrometry; Dallas, 1969; p. 80-82.

32. Yost, R. A.; Enke, C. G. I. Am. Chem. Soc. 1978, 100, 2274; McGilvery, D. C.; Morrison, J. D. Int. I. Mass Spectrom. Ion Phys. 1978, 28, 81 .

33. Cooks, R. G.; Kaiser, R. E., Jr. Acc. Chem. Res. 1990, 23, 213.

34. (a) Gross, M. L.; Russell, D. H. In Tandem Mass Spectrometry; McLafferty, F. W.; Ed.; Wiley: New York, 1983, pp. 255-270; (b) Todd, P. J.; McGilvery, D. C.; Baldwin, M. A.; McLafferty F. W. In Tandem Mass Spectrometry; McLafferty, F. W., Ed.; Wiley: New York, 1983; pp. 271-286.

35. Hillenkamp, F.; Karas, M.; Beavis, R. C.; Chait, B. T. Anal. Chem. 1991, 63, 1193A.

36. Fenn, J. B.; Mass, M.; Meng, C. K.; Wong, S. F.; Whitehouse, C. M. Science 1989, 246, 64

37. McLafferty, F. W. Acc. Chem. Res. 1994, 27, 379-386.

38. Guan, S.; Kim, H. S.; Marshall, A. G.; Wahl, M. C.; Wood, T. D; Xiang, X. Chem. Rev. 1994, 94, 2161-2182.

39. Chen, R.; Cheng, X.; Mitchell, D. W.; Hofstadler, S. A.; Wu, Q.; Rockwood, A. L.; Sherman, M. G.; Smith, R. D. Anal. Chem. 1995, 67, 1159-1163.

40. Marshall, A. G.; Wang, T.-C. L.; Ricca, T. L. J. Am. Chem. Soc. 1985, 107, 7893-7897.

41. O'Conner, P. B.; Little, D. B.; McLafferty, F. W. Anal. Chem. 1996, 68, 542-545.

42. Wood, T. D.; Chen, L. H.; Kelleher, N. L.; Little, D. P.; Kenyon, G. L.; McLafferty, F. W. Biochemistry 1995, 34, 16251-16254.

43. Valaskovic, G. A.; Kelleher, N. L.; McLafferty, F. W. Science 1996, 273, 1199-1202.

44. Mortz, E.; O'Connor, P. B.; Roepstorff, P.; Kelleher, N. L.; Wood, T. D.; McLafferty, F. W.; Mann, M. Proc. Nat. Acad. Sci U.S. A. 1996, 93, 8264-8267. 